\title{
Comparison of Different Pulmonary Valve Reconstruction Techniques During Transannular Repair of Tetralogy of Fallot
}

\author{
Bahar Temur ${ }^{1}$, Selim Aydın ${ }^{1}$ Dilek Suzan ${ }^{2}$, Barıs Kırat $^{3}$, Halil Demir ${ }^{4}$, and Ersin Erek ${ }^{1}$ \\ ${ }^{1}$ Acibadem Universitesi Tip Fakultesi \\ ${ }^{2}$ Yeni Yuzyil University Gaziosmanpaşa Hospital \\ ${ }^{3}$ Istanbul Florence Nightingale Hospital \\ ${ }^{4}$ Dr Siyami Ersek Thoracic and Cardiovascular Surgery Training and Research Hospital
}

June 22, 2020

\begin{abstract}
Background: Transannular patch, which results pulmonary insufficiency (PI), is usually required during repair of Tetralogy of Fallot (TOF). In this study, we compared 3 types of pulmonary valve reconstruction techniques during transannular repair of TOF. Methods: Between February 2014 and January 2018, 50 patients with TOF underwent total repair with transannular patch. These patients were divided into three groups. In group $1,(\mathrm{n}=15)$, a single gluteraldehyde treated autologous pericardial monocusp (standard method) was reconstructed. In group 2, $(\mathrm{n}=16)$ Nunn's bileaflet pulmonary valve reconstruction technique was used with autologous pericardial patch. In group $3,(n=19)$, Nunn's bileaflet technique was performed with expanded polytetrafluoroethylene (e-PTFE) membrane. Outcomes of the patients with early and mid-term competency of the pulmonary valves were analyzed. Results: All three pulmonary valve reconstruction techniques were significantly effective in early postoperative period. Freedom from moderate to severe PI were $73.3 \%$; $100 \%$ and $89.4 \%$ respectively. Mortality, duration of intensive care unit and hospital stay were similar between the groups. The mean follow-up period was $17.5 \pm 13.0$ (3 to 57 ) months. Freedom from moderate to severe PI decreased to $40 \%$; $81.2 \%$ and $73.7 \%$ respectively at the end of the follow-up period. Presence of moderate to severe PI was significantly higher in group 1 (p: 0,018 between group 1 and 2, p: 0,048 between group 1 and grup 3). Conclusions: All three pulmonary valve reconstruction techniques provided competent pulmonary valves. Nunn's bileaflet technique had better outcome at midterm. This technique has a potential to delay right ventricular dysfunction at long-term.
\end{abstract}

\section{Hosted file}

Comparison_of_Different_Pulmonary_Valve_Reconstruction_Techniques_During_Transannular_Repair_of_-Tetral available at https://authorea.com/users/335651/articles/461489-comparison-of-differentpulmonary-valve-reconstruction-techniques-during-transannular-repair-of-tetralogy-offallot 

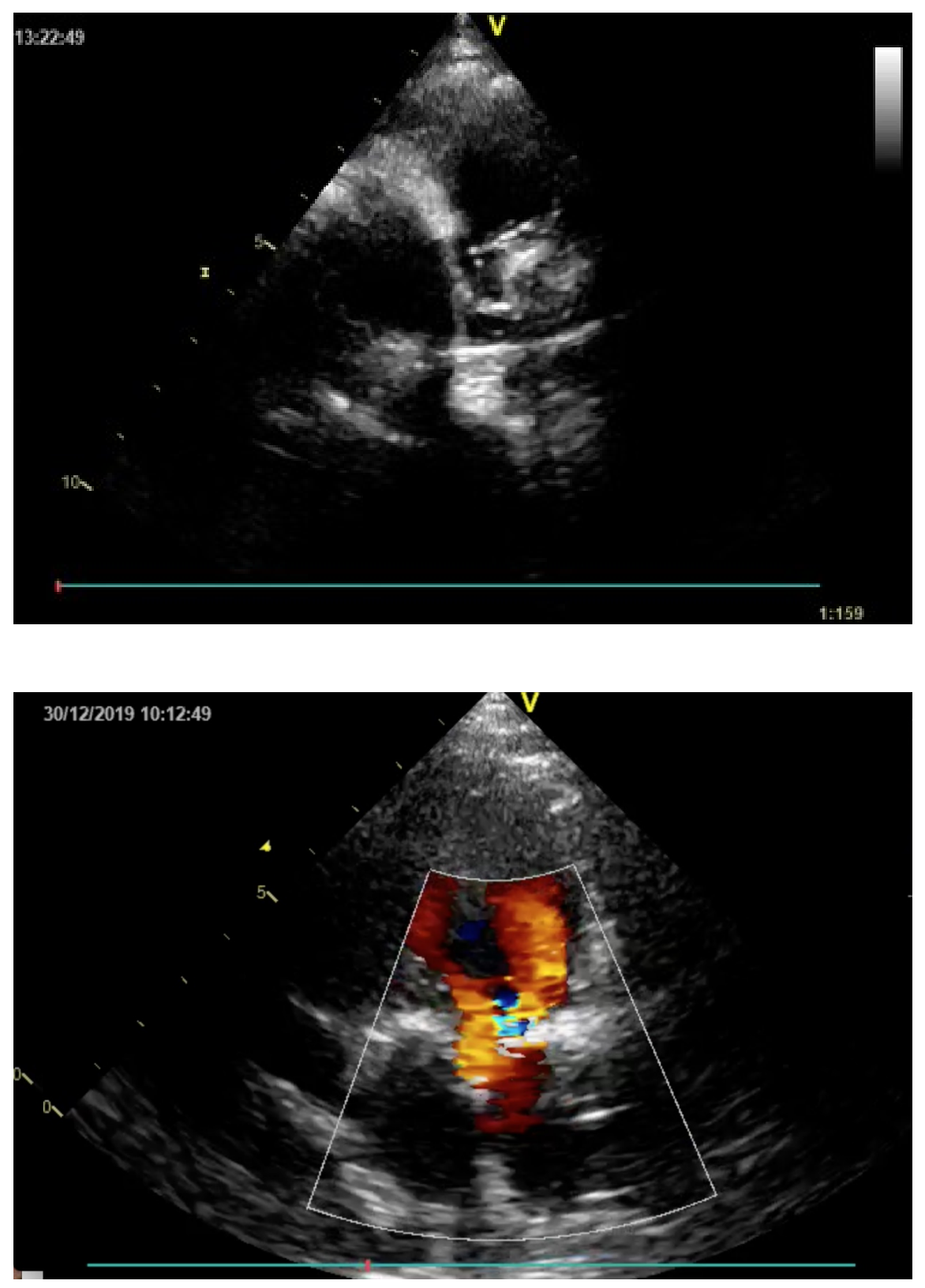